\title{
CIUDADANO VS. CONSUMIDOR: SIGNIFICADO DEL CONSUMO EN EL POSTCAPITALISMO DE STREECK
}

Citizen vs. Consumer: Meaning of Consume in Streeck's Postcapitalism

\author{
Álvaro Ramos Colás \\ Universidad Nacional de Educación a Distancia \\ aramos177@alumno.uned.es
}

\section{Resumen:}

En el presente artículo nos gustaría mostrar la postura de uno de sus más prominentes teóricos del postcapitalismo, Wolfgang Streeck, haciendo especial énfasis en el papel que el consumo ha jugado en el paso de la sociedad fordista a la posfordista. Su posición será contrastada con la de otros estudiosos de los cambios sociales y políticos que se han venido operando desde la posguerra. Para todos ellos parece claro que el consumo es un asunto clave en la transformación de la sociedad, aquí trataremos de esbozar es en qué sentido lo es.

\section{Palabras clave:}

Postcapitalismo, consumo, mercados, ciudadanía, democracia, posfordismo.

\begin{abstract}
:
In this paper I would like to present one of the most prominent theorits of postcapitalism, Wolfgang Streeck, making especial reference to the roll the consumption has been playing in the process from the Fordist to the postfordist society. His thesis will be compared with other points of view about those socio-political changes that happened since the end of the World Word II. The consumption seems to have been of key factor in that process. In this article I will try to present the sense of this importance.
\end{abstract}

\section{Keywords:}

Postcapitalism, Consumption, Markets, Citizenry, Democracy, Posfordism.

Recibido: 28/10/2018

Aceptado: 15/12/2018 


\section{INTRODUCCIÓN}

Hasta la irrupción de la crisis económica en 2007 existía un amplio consenso según el cual la democracia y crecimiento económico iban de la mano. Gabriel Tortella, en los albores del siglo XXI, afirmaba que «históricamente la democracia ha avanzado a medida que se desarrollaban las economías» (Tortella, 2000: 385). La Gran Recesión ha puesto en entredicho esta afirmación, aportando al debate ideas que hasta hace poco parecían recluidas a ciertos grupos radicales o a algunos intelectuales especialmente resentidos con el capitalismo, con la democracia liberal o con ambos. En primer lugar, sí que parece cierto que, cuando la economía deja de funcionar (alta inflación, desempleo, falta de crecimiento, etc.), se genera un caldo de cultivo contra la democracia en forma, entre otras cosas, de populismos de muy distinto signo. El ascenso actual en gran parte de Europa de la extrema derecha es buena muestra de ello. Aunque este extremismo siempre ha estado presente desde finales de la década de 1920, la falta de oportunidades y de expectativas, los recortes sociales, los rescates bancarios, etc. ${ }^{1}$ han multiplicado su número de votantes atraídos por los cantos de sirena del neofascismo.

Pero, si leemos de otro modo la cita de Tortella, nos asalta una duda intrigante. Si el desarrollo de la economía y la democracia han ido históricamente de la mano, ¿cómo conjugar los retrocesos democráticos y el ascenso del populismo nacionalista y xenófobo de algunos de los países con economías en crecimiento aceptable, bajo desempleo y altos niveles culturales? Alemania, Reino Unido, Austria, Holanda, aunque también Polonia y Eslovaquia, por citar solo algunos casos, pueden ser tomados como ejemplos que contradicen en parte la tesis generalmente aceptada según la cual, los problemas de la democracia suelen ser causados por problemas de desarrollo económico. Es solo cierta en parte. En este artículo veremos cómo la democracia también puede ser arruinada por intereses privados, cómo en la actualidad, de hecho, el mismo "progreso económico" la está poniendo en riesgo y cómo la nueva sociedad posfordista ha creado un individuo hedonista y apolítico, cuya toma de decisiones vitales reflejan las actitudes consumistas predominantes, muy alejadas del compromiso social que se le supone al ciudadano (pieza clave de las democracias liberales). El papel del consumo es, por ende, clave en este proceso, por lo que se entiende, tal como defiende el profesor Luis Enrique Alonso (2005), que el consumo es mucho más que una variable de la demanda agregada es una expresión de disposiciones colectivas, de luchas de poder y, cómo no, de apropiación de excedente.

Nos centraremos en el trabajo de uno de los principales sociólogos alemanes de la economía en la actualidad, Wolfgang Streeck, quien plantea estas cuestiones, a nuestro juicio, con agudeza y profundidad. A su vez, hemos creído interesante contrastar sus puntos de vista con otros autores como Colin Crouch, Gilles Lipovetsky y Zygmunt Bauman, quienes se han tomado muy en serio estos asuntos y plantean matices que enriquecen decisivamente el estudio de la cuestión.

\footnotetext{
${ }^{1}$ Lo que Oliver Nachtwey ha denominado "la modernidad regresiva" (2017. Agradezco a Ramón del Castillo la referencia bibliográfica).
} 
En la primera parte del artículo introduciremos las tesis de Streeck sobre el proceso de conquista del poder de los mercados a expensas de los ciudadanos de a pie. En la segunda, veremos su posición respecto al consumo y el papel que juega en el engranaje social. En el último esbozaremos brevemente algunas de las perspectivas que se abren a raíz de lo tratado en el ensayo.

\section{MARKTVOLK VS STAATSVOLK: DEL FORDISMO AL POSTINDUSTRIALISMO}

Muy a menudo se ha definido la época que va desde el final de la Segunda Guerra Mundial hasta las crisis del petróleo $(1973,1979)$ como la época dorada del fordismo, del Estado social y del keynesianismo, pero la descripción quedaría incompleta si nos limitamos a esta afirmación. El keynesianismo fue, al menos en aquella época, algo más que un conjunto de teorías económicas. Por ejemplo, el concepto de Estado del bienestar, piedra angular de numerosas sociedades de posguerra, era entendido por los empleadores y por los trabajadores como el modo más justo de organizar materialmente la sociedad. En este sentido, las aspiraciones laborales de los trabajadores no eran consideradas como meras mejoras materiales, sino un derecho legítimo y democrático que asistía a cualquier persona que viviera de su trabajo (Streeck, 2017: 26). ${ }^{2}$

Del mismo modo, las instituciones que mediaban entre trabajadores y empleadores eran consideradas necesarias para el mantenimiento del ecosistema capitalista de la época y, por consiguiente, garantes indispensables de la justicia social. En gran medida, pese a las grandes divergencias ideológicas entre la derecha y la izquierda democrática de aquellos años, podría decirse que ambas compartían una idea de justicia social que trascendía lo político y que sólo era discutida por grupos de partisanos situados muy a la izquierda o muy a la derecha del amplio consenso imperante.

En cualquier caso, no nos gustaría describir estos años como una Arcadia feliz libre de conflictividad social. Según la propia teoría de Streeck, un período sin conflicto de clases en una sociedad capitalista es simplemente imposible. La principal diferencia radica en que, a diferencia de hoy en día, las aspiraciones de los trabajadores eran consideradas normalmente como democráticas. En el presente apartado trataremos de exponer cómo se ha pasado de ese modo de entender el conflicto social en aquella época a la abierta y desigual confrontación de la nuestra.

Streeck indica dos grandes motivos que explican el fin de la época dorada del keynesianismo de posguerra: las revueltas de 1968 y las crisis del petróleo (ib.: 37). Las violentas revueltas, según el sociólogo alemán, abrieron los ojos de los dueños y administradores del gran capital, al hacerles entender que la mayor parte de la conflictividad laboral se debía a una radicalización del discurso de lucha de clases que, muy probablemente, desembocaría en una descompensación permanente de la balanza social en su contra.

\footnotetext{
${ }^{2}$ N. Luhmann, en Political Theory in the Welfare State, afirma que el Estado del bienestar es la realización misma de la inclusión política.
} 
Por lo que respecta a la crisis de 1972 su influencia fue menos psicológica, aunque no por ello menos determinante. El período de posguerra se definió, entre otras cosas, por el alto crecimiento del PIB, lo cual permitía que una redistribución de la renta no perjudicara demasiado a los dueños del capital. Pero cuando este crecimiento se agotó, las clases que dependían de los rendimientos del capital se vieron obligadas a intentar conservar su (gran) porción del pastel, lo cual sólo podía conseguirse a costa de los trabajadores. Así surgió una corriente de opinión a finales de los 60 que abogaba por la necesidad general de liberalización de la economía y flexibilización de los mercados, y que fue a la postre el inicio del neoliberalismo actual.

Ya tenemos planteados, si bien embrionariamente, los actores principales de la pugna que, según Streeck, definen la sociedad capitalista. Su otro elemento definidor es el ámbito institucional, donde el Estado es el principal agente. Según el relato de Streeck (2009: 7 ss.), el Estado es una especie de árbitro que media entre las partes contendientes. Hasta finales de los 60 , cuando todavía el alto crecimiento económico lo permitía, su principal tarea era la de redistribuir riqueza. Claro que, cuando eso dejó de ser posible, tuvo que "apaciguar" a los perjudicados por la nueva situación macroeconómica (los trabajadores), aunque eso sí, sin damnificar a los poseedores del capital. Este es el punto de partida del relato de Streeck. Después del estallido de la crisis del 73, el Estado se vio obligado a calmar a ambos bandos, aunque siempre posponiendo la solución con una política de parches. Por eso habla de "comprar tiempo", porque lo único que se consiguió con estas soluciones temporales fue posponer el fin del sistema, el cual, de haber sido abandonado a su desarrollo normal, habría sucumbido hace ya algún tiempo.

Podría afirmarse que, en el inicio de la contienda entre dueños y gestores del gran capital contra los trabajadores, la crisis no fue sólo la causa de la toma de conciencia de la situación de conflicto, sino que fue la razón perfecta para empujar al Estado a realizar políticas que favorecieran a los primeros. En concreto, el panorama económico de las principales economías en los años 70 estuvo marcado por un bajo crecimiento y alta inflación (por el encarecimiento del petróleo), lo cual espoleó al Estado a buscar soluciones interviniendo en la economía de un modo distinto a como lo había hecho hasta finales de los 60 (Ib., 34). Se impuso el criterio macroeconómico que dictaba subir tipos de interés, y así se llevó a la práctica con el "shock" de Paul Volcker (alentado por Reagan), que elevó los tipos de interés hasta el 20\%. La agonía del Estado de bienestar había comenzado.

Las consecuencias no se hicieron esperar. Por un lado, los dueños del capital vieron cómo la retribución de este aumentaba considerablemente sin necesidad de tener que arriesgarlo en otro tipo de actividades. Esto detrajo recursos financieros de la "economía real", con el consiguiente aumento del desempleo, lo cual Ilevó aparejada una pérdida de capacidad negociadora de los trabajadores. ${ }^{3}$ A pesar de este debilitamiento de los sindicatos, la tensión social se disparó, lo cual obligó al Estado a "comprar tiempo", es decir, a intentar posponer el problema sin solucionarlo. La tentativa consistió en la mayoría de las economías occidentales en mantener los

${ }^{3}$ El "ejército de reserva", en palabras de Marx, presiona a la baja salarios y hace menos viable la fuerza negociadora frente a la clase social dominante. 
niveles de gasto público, aumentando las prestaciones sociales por desempleo y de protección social a las clases que más estaban sufriendo los rigores de la crisis.

Esto generó un aumento vertiginoso de la deuda, y dio paso a la primera gran transformación del Estado en la posguerra, según Streeck. Si hasta entonces los Estados occidentales se habían limitado, en palabras de Schumpeter, ${ }^{4}$ a recaudar para redistribuir (lo que se conoce como tax state o Estado fiscal), esa función dejó de ser una descripción de sus atribuciones apropiada. A partir de ese momento pasó a ser un debt state, es decir, un Estado deudor, ya que se vio obligado a endeudarse para seguir manteniendo ciertas coberturas sociales para mantener la paz social, amenazada por la nueva marea de desocupados. Para contentar a la clase dependiente de los rendimientos del capital (los inversores) se realizaron privatizaciones de servicios públicos, se bajaron los impuestos a las clases altas, etc. (Streeck, 2017: 78). ${ }^{5}$

Todas estas medidas, que en apariencia perseguían "mediar" entre unos y otros, no hicieron sino agrandar las diferencias entre ambos grupos, dado su descarado sesgo a favor de las élites económicas. En cualquier caso, más allá de las graves consecuencias materiales que supusieron, Streeck introduce un matiz más agudo en la división entre las clases confrontadas. La nueva situación social en este estadio del capitalismo está, según el sociólogo alemán, definida por la pugna entre lo que él denomina Staatsvolk o ciudadanía y Marktvolk o mercados/inversores (Streeck, 2017: 81). ${ }^{6}$ La gran diferencia respecto a la etapa anterior, la del Estado fiscal, es que la batalla se plantea en una situación de desigualdad mucho mayor por los motivos aducidos y, además, porque la ideología empieza a jugar un papel más importante todavía que en la época dorada de posguerra. En términos generales, podría afirmarse que la pugna ideológica se hace completamente autónoma de los hechos sociales y económicos. Por un lado, el Marktvolk defiende la "libertad del individuo" sobre todas las cosas, y sin embargo, no pierde oportunidad para aumentar su influencia sobre las políticas públicas, lo cual conllevó un empobrecimiento radical de la democracia. Algo totalmente evidente, y que desde la década de los 80 hasta la actualidad no ha hecho más que empeorar, ha sido el hecho de la dependencia de los Estados (donde

\footnotetext{
${ }^{4}$ En 1918, Schumpeter escribió su famoso artículo "The Crisis of the Tax State", en el cual, ya una década antes del crac del 29, se hacía una simple pregunta (pero no por ello menos profunda): ¿El Estado fiscal está condenado a la bancarrota? Ha pasado mucho tiempo desde que lo escribiera, y ha quedado claro que muchas de sus predicciones, a la luz de la historia y después de tantas crisis que hemos padecido desde entonces, que la respuesta es negativa, tal y como indicó Musgrave (1992). Pero lo más interesante del artículo es, por supuesto, la intuición que le lleva a esa pregunta, y no en menor medida el enfoque tan avanzado acerca de la "sociología fiscal" que propone. Con grandes diferencias, ahí podemos situar otra de las fuentes de la sociología económica crítica de Streeck.
}

${ }^{5}$ Como complemento al trabajo de Streeck, especial en lo que respecta a datos concretos, véase Piketty (2015).

${ }^{6}$ A lo largo de nuestra exposición mantendremos la nomenclatura original en alemán, que es la que se ha mantenido también en el texto en inglés. 
reside teóricamente la voluntad popular) respecto a los inversores, o lo que es lo mismo, del Staatsvolk al Marktvolk. ${ }^{7}$

Streeck presenta algunas características que aclaran las grandes diferencias entre ambas clases y que muestran a la perfección la descompensación entre las cuotas de poder que cada una ostenta. El Staatsvolk es de ámbito nacional, emana de la voluntad de la ciudadanía y de las elecciones libres, considera los derechos civiles la base de toda convivencia, también que la opinión pública y la prensa libre son dos contrapoderes imprescindibles, y aspira en líneas generales a obtener del Estado servicios públicos de calidad a cambio de los impuestos pagados. Por contra, el Marktvolk se mueve a escala planetaria, son inversores, su poder (que no legitimidad) emana de los mercados y del capital, asume que sus exigencias económicas son la base de un contrato social legítimo y que ningún contrapoder se puede oponer a la lógica de los mercados.

La lucha entre ambos grupos supuso un giro sustancial en las relaciones entre capitalismo y democracia, sentando las bases del neoliberalismo actual. Streeck apunta a un hecho que Ulrich Beck ya había intuido como un "riesgo" sobresaliente a finales del siglo XX (Beck, 2015), a saber, la pérdida de soberanía nacional que la globalización neoliberal conllevaba. Directa o indirectamente, los inversores (Marktvolk) pueden presionar a los gobiernos para que adopten políticas que les beneficien, ya que, sin sus préstamos, países cuyas deudas públicas superen ampliamente el PIB, literalmente deberían declarar la bancarrota (Streeck, 2017: 85). ${ }^{8}$

Los remiendos diseñados en la década posterior a las crisis del petróleo sirvieron para calmar durante una década la guerra abierta entre el Staatsvolk y el Marktvolk, pero no para esquivar la profecía de Ralph Miliband. ${ }^{9}$ El principal problema al que se enfrentaron (y siguen haciéndolo) los gobiernos democráticos fue el aumento exponencial de la deuda. Lógicamente, los inversores, que no tienen patria, centraron gran parte de sus esfuerzos en asegurarse los retornos del capital comprometidos por los grandes volúmenes de deuda pública.10 Desde la década de los 90 hasta la actualidad, los Estados fueron forzados a implementar políticas económicas y sociales

\footnotetext{
7 Por ejemplo, de inversores públicos y privados en deuda soberana, agencias de rating, instituciones supranacionales como el FMI, el Banco Mundial, etc.

${ }^{8}$ Recordemos con qué celeridad, por ejemplo, se aprobó en España la reforma constitucional para asegurar el techo de la deuda constitucionalmente en el año 2011.

9 Miliband (2015) publicó el famoso artículo "Class War Conservatism" al año de llegar Thatcher al poder. En él indicó que todas las medidas liberalizadoras que se estaban emprendiendo no eran coyunturales, sino que correspondía a un proyecto político e ideológico a largo plazo. Así fue.

10 Lo irónico del asunto es que estas montañas de deuda no se generaron por la implementación de políticas de corte neokeynesiano. De hecho, el Estado del bienestar tendió a recortarse paulatinamente y sin descanso desde entonces. El problema del endeudamiento surge cuando esos recortes se producen a un ritmo menor que las bajadas de impuestos a las clases altas. Menores ingresos con gastos prácticamente constantes implican aumento de la deuda (Streeck, 2014).
} 
que aseguraran la devolución de la deuda. Es lo que Streeck ha denominado "Estado consolidado."

Además de los recortes en políticas sociales, el Estado consolidado debió acometer políticas económicas para apaciguar al Marktvolk, aunque muchas de ellas supusieran mayores pérdidas de calidad en las democracias nacionales. Tal como afirma el profesor Palazuelos, el sistema capitalista actual se define por ser transnacional y financiarizado (Palazuelos, 2015: 303 ss.), y ese es también el eje que vertebra la explicación streeckiana de lo sucedido desde los 90. En realidad, ambas características van de la mano. Sería muy difícil imaginar que la actuación del Marktvolk pudiera circunscribirse al ámbito nacional y que aun así ostentara el poder de coacción que disfruta en la actualidad. El gran capital basa su fuerza en no conocer límites, lo cual posibilita asociaciones y sinergias imposibles de contrarrestar para los Estados. Por ello, una de las luchas principales del Marktvolk ha sido liberalizar a escala global los movimientos de capitales. Ahí es donde la globalización y la financiarización se retroalimentan. El capital global impide cualquier acción que limite su libertad de movimientos o su "creatividad" financiera (nuevos productos indescifrables para los pequeños inversores, facilidades de créditos instantáneos, viviendas hipotecadas más de una vez, etc.), y eso se consigue limitando las soberanías populares nacionales.

La financiarización dio una sensación a los ciudadanos de a pie (Staatsvolk) de bienestar ficticio, que funcionó hasta que la burbuja de crédito privado explotó en 2007. ${ }^{11}$ Streeck analiza este período como la siguiente componenda de los legisladores para mantener la sociedad capitalista con las mínimas constantes vitales. Toda vez que los Estados no podían seguir pagando la factura del Estado del bienestar (estaban demasiado endeudados y los inversores le exigían garantías de devolución de lo adeudado), la única solución para que las clases antes favorecidas por los sistemas de protección social no vieran empeorarse sus niveles de vida (con la consiguiente conflictividad que eso acarrearía), fue favorecer el crecimiento del crédito privado, es decir, liberalizar casi por completo el mercado de capitales. Esto es lo que Colin Crouch (2011) Ilamó "keynesianismo privado." En definitiva, la idea era que el sector privado, mediante la expansión del crédito, mantuviera los estándares de vida que el Estado no podía seguir brindando a las clases menos pudientes. $^{12}$

Christian Laval y Pierre Dardot $(2013,2017)$, han extraído las consecuencias más importantes de este conjunto de políticas, que se llevaron a cabo para reforzar el patrón de globalización más financiarización, y que se conocen con el nombre un tanto confuso de "neoliberalismo." Coinciden a grandes rasgos con el análisis del momento actual de Streeck, en especial en lo que respecta a la relación antagónica entre el neoliberalismo y la democracia. El neoliberalismo es la ideología de la

\footnotetext{
${ }^{11}$ Los asalariados disponían de liquidez, pero a costa de endeudarse muy por encima de lo que sus rentas, teóricamente, les permitían.

12 Por supuesto, este fue un proceso paulatino, y no en todos los países ha tenido la misma profundidad, pero hay que recordar que Streeck habla, en general, de los Estados capitalistas occidentales, lo que toma en consideración desde EE. UU. hasta los países escandinavos.
} 
oligarquía, mientras la democracia, recuerdan los autores siguiendo la definición aristotélica, es "el gobierno de los pobres para los pobres" (Laval y Dardot, 2017: 21). Según esta definición, los intereses de los distintos grupos sociales se oponen, lo que se refleja en la constitución política de la sociedad. El gobierno de las élites (Marktvolk) sería la oligarquía, y el de los desfavorecidos, la democracia. En este sentido, ha quedado cada vez más claro desde la radicalización del neoliberalismo emprendida a principios de la década de los 80 con el inicio del Estado deudor (Streeck), que la democracia liberal era más bien una oligarquía liberal, y que la ideología de los mercados autónomos regidos por sí mismos, en la práctica no ha sido sino una quimera. La crisis mundial de 2008 ha supuesto, como no podría ser de otro modo en opinión de Laval y Dardot, un nuevo giro y más sofisticado en las estrategias encaminadas a defender los intereses de las élites. Es lo que ellos denominan "la crisis como modo de gobierno", que consiste en el modo en que gobierna la oligarquía para afianzar los anclajes que sustentan su poder político y económico. La táctica es clara: o se pliega el gobierno en cuestión a las recetas neoliberales o le será casi imposible financiarse exteriormente, haciendo que los servicios más básicos del Estado no puedan ser costeados. En resumen, los autores defienden que la crisis es el arma más poderosa con que cuentan las élites para conseguir sus objetivos, y, por tanto, les resultan muy rentables los estados de excepción de dichos períodos (ib.: 25). En este sentido habla Streeck de dos justicias: la social y la de los mercados, que se corresponde respectivamente con la ciudadanía o Staatsvolk y con los propietarios del gran capital o Marktvolk (Streeck, 2017: 58 ss.).

El ejemplo de Syriza en Grecia es paradigmático, ya que al poco tiempo de ganar las elecciones se vio forzada, debido a la crisis galopante que azotaba al país, no solo a renunciar a sus principios políticos fundamentales, sino a aceptar la agenda neoliberal (privatizaciones, recortes en las políticas de gasto social, aumento de la edad de jubilación, etc.). El gran error de Tsipras fue creer que la lógica del neoliberalismo a la que se enfrentaba podría ser combatida desde otra opuesta igualmente racional (Laval y Dardot, 2017: 115). Nada más lejos de la realidad, las imposiciones de la Unión Europea (institución defensora de los postulados neoliberales por antonomasia también en opinión de Streeck) eran del todo arbitrarias, al ser la exigencia de la devolución de la deuda al completo a todas luces irrealizable y responder a intereses puramente privados. Lo que se buscaba, siempre según Laval y Dardot, era el sometimiento por la fuerza y no mediante ningún tipo de argumento racional, por más que a veces dichas exigencias se revistieran de ciencia económica indiscutible. En consecuencia, hay algo más que intereses económicos a corto plazo (el pago de la deuda): la reorganización de la sociedad de tal modo que se perpetúe la dominación oligárquica y, de este modo, sus intereses económicos a largo plazo. Ambos autores franceses coinciden, por tanto, con la tesis de fondo de Streeck según la cual el capitalismo no es simplemente un asunto económico, sino social en un sentido amplio.

Pero Streeck va más allá, de este proceso que hemos venido explicando y que se corona con el Estado consolidado y la crisis de 2008, extrae la tesis de que, de hecho, estamos llegando al fin del capitalismo. En cualquier caso, el fin del capitalismo no implica el fin de la propiedad privada, ni del comercio, ni de la globalización. Streeck parte de la concepción weberiana del capitalismo como conflicto perpetuo y por eso 
defiende que el capitalismo, como sistema político y social, está llegando a su fin, porque ya no existe confrontación entre grupos sociales que compitan descarnadamente por una proporción mayor de la riqueza; esa será la razón del fin de la sociedad capitalista (Streeck, 2016a: 35). Podría decirse que los factores estabilizadores del sistema capitalista son los equilibrios entre fuerzas contrarias y que, al ser una de ellas eliminada del tablero, no habrá equilibrio posible, puesto que una de ellas se habrá impuesto a la otra. En cualquier caso, esta afirmación de Streeck no debe ser entendida como un deseo de concordia entre los distintos grupos sociales, los cuales debería llegar a la conclusión de que colaborar es mejor que competir. Lo que propone Streeck es justo lo contrario: el capitalismo es conflicto de intereses y, hoy en día, ese conflicto no existe, toda vez que el Marktvolk ha derrotado al Staatsvolk. Dicho de un modo más crudo, el capitalismo está desapareciendo ante nuestros ojos porque una de las facciones ha conseguido (casi) todo el poder al hacerse dueña y señora de todos los resortes (instituciones) que posibilitan un cierto equilibrio social.

Sin embargo, Streeck no cree que hayamos llegado al escenario final de descomposición de la sociedad capitalista, sino que nos estamos aproximando a él. La visión de la sociedad postcapitalista, eso sí, no es nada halagüeña. Lejos de suponer una liberación, Streeck cree que nos adentramos en un interregno sin signo fijo (Streeck, 2016b), una especie de pandemónium social dominado por el desorden y bajo el único dictado de la facción victoriosa (ib.: 35-36). En palabras de Streeck es "algo menos que una sociedad", una "sociedad postsocial."

Este interregno podría ser definido como la desintegración del nivel macro de la sociedad, de tal modo que los individuos se ven impedidos a nivel micro para autoorganizarse. En este sentido, Streeck opina que vivimos en una sociedad "desinstitucionalizada" o, en el mejor de los casos, "infrainstitucionalizada" (ib.: 36), lo cual la hace ingobernable. Esta es una de las consecuencias más graves, la atomización de los individuos al haber perdido el acceso a las instituciones que les servían anteriormente de contrapeso y de control de las élites. Streeck ve en la ofensiva neoliberal iniciada por Reagan y Thatcher un programa completo conducente a la desposesión del ciudadano: las deslegitimaciones de los sindicatos y de las políticas sociales, reducción considerable del tamaño institucional de los Estados, redefinición de fronteras, etc. Todas estas medidas tienen como objetivo desarmar al ciudadano mediante la desinstitucionalización de la sociedad capitalista heredada de la posguerra.

El principal problema, tal y como venimos apuntando, es el peligro de disolución de la sociedad capitalista que este proceso implica. Desde el momento en que las élites económicas consigan deshacerse de la contraparte en la "dialéctica" del funcionamiento capitalista (ciudadano o Staatsvolk), ya nada será como antes, ni tan siquiera podremos hablar de una sociedad, sino de postsociedad. ${ }^{13}$

\footnotetext{
13 Podría ser interesante comparar este término con el de "riesgo" que Ulrich Beck trazó en La sociedad del riesgo. Según este texto ya canónico, la modernidad había llegado a un punto de perplejidad difícil de superar a finales del siglo xx. Por un lado, habíamos llegado a tener la capacidad técnica de asegurarnos el bienestar material, pero por otro, descubrimos para
} 


\section{DEL CIUDADANO AL CONSUMIDOR}

En los apartados anteriores hemos presentado el desarrollo del conflicto social desde el fin de la Segunda Guerra Mundial hasta nuestros días desde la perspectiva de Streeck. En este presentaremos las principales tesis de Streeck acerca del consumo y, en especial, cómo ha modelado la fisionomía de la ciudadanía. En el relato de Streeck no se encuentran muchas trazas de la influencia del consumo en la batalla entre ciudadanía y mercados, ${ }^{14}$ lo cual no significa que en su opinión carezca de importancia, como muestra el artículo "Citizens as Customers" dedicado a este aspecto (2016a). En concreto, el papel del consumo nos ayudará a entender cómo el ciudadano de esta postsociedad ha dejado de serlo para pasar a ser un consumidor, ahondando así en la desinstitucionalización a la que hace mención Streeck.

Lipovetsky (2016: 328-329) no ve en la metamorfosis del ciudadano al consumidor algo excesivamente negativo en sí mismo, sino un cambio que, en cierto modo, ha ayudado mediante la expansión del consumismo hipermoderno a romper con muchas de las cadenas de la civilización "pesada" (la del fordismo de posguerra). En oposición a la ligereza actual, la etapa anterior requería de un consumo más racional, encaminado a una satisfacción de unas necesidades claramente delimitadas y solía estar enlazado a un proyecto vital más o menos previsible. Si pensamos en los parámetros de consumo de la posguerra mundial, parece claro que tanto la producción de bienes como la organización de las vidas de los individuos estaba orientada a la racionalización de la existencia material: trabajo seguro, consumo para cubrir necesidades nítidamente delimitadas, vida cultural estable y asociacionismo de clase componían un todo racional que se denominó "fordismo". Como no puede ser de otro modo, el fordismo, culmen de la civilización de posguerra, acarreaba también unos valores, que a su vez eran deudores del proyecto de la modernidad. Estos valores se resumen en "las antiguas formas de obligación religiosa, familiar, sexual, política» $y$, de hecho, «la jaula dorada del consumo ha funcionado y sigue funcionando como un potente vehículo de autonomización de las personas, y esto incluso lejos de la esfera del consumo» (id.).

nuestro desasosiego que, en realidad, la modernidad no consistía sólo en eso. Las promesas de la sociedad industrial se habían revelado insuficientes para dotarnos de la seguridad ansiada. Tanto en el terreno de lo político, social, legal, económico, ecológico, etc. surgían "riesgos" que, en efecto, tenían un carácter muy distinto de los que hasta entonces se habían tenido en consideración. El enfoque de Streeck va un paso más allá, a saber, plantea una sociología del "fin", o mejor dicho, "del ocaso"; ya no hablamos de riesgos o situaciones problemáticas características de una época, sino de una sociedad que se apaga y que dará lugar a otra. La diferencia de enfoques en este punto es la que va de la descripción del problema (Beck) a la anticipación de algo radicalmente nuevo que no merece ni tan siquiera el nombre de "sociedad".

${ }^{14}$ Su ámbito de estudio se mueve en lo macro, en las políticas económicas y las motivaciones que las animan, pero reconoce la importancia de lo micro, como muestra su interés en el consumo. 
Streeck coincide con Lipovetsky en el diagnóstico de los cambios del patrón del comportamiento de los consumidores, pero su valoración es bastante más negativa. ${ }^{15}$ El sociólogo alemán localiza en torno a 1972 (primera crisis del petróleo) el inicio del giro del consumidor fordista al posfordista. El sujeto perteneciente a la sociedad de posguerra, obligado por la producción estandarizada en masa, se ve obligado a adquirir entre una gama muy corta de productos. Una vez cubiertas las principales necesidades, y al no haber muchas alternativas apetecibles, no hay un incentivo para seguir consumiendo. Esta caída del consumo podría redundar en una desaceleración de la economía, y, muy probablemente, en una recesión (Streeck, 2016a: 98). El objetivo para la reactivación debería pasar por aumentar la oferta de bienes y servicios que empujara al consumidor a adquirir "nuevos" productos, los necesitaran o no. Había que pasar del consumo monocromo fordista a algo más desestandarizado donde el comprador experimentara la necesidad de consumir por consumir. Ya no había que cambiar de coche porque el antiguo se estropeara a menudo, sino porque el modelo dos años más reciente tenía una funcionalidad (o un color, o un embellecedor, etc.) del que carecía el anterior.

Como apuntábamos en el apartado anterior, la década de los 70 supuso, en opinión de Streeck, el paso del Estado impositivo al Estado endeudado, dado que el Estado pretendía mantener el poder adquisitivo de las clases más desfavorecidas mediante transferencias y servicios que los ingresos públicos no podían cubrir. La instauración de esta nueva cultura consumista, además de expandir el consumo, apoyaría los objetivos de apaciguar la agitación social, puesto que ayudaría a crear una cultura consumista que, tal y como indicó Zygmunt Bauman (2009: 115 ss.), estaría centrada en el presente y en el exceso de la compra compulsiva. En este sentido, tanto para Bauman como para Streeck, un concepto clave sería el de socialización. ${ }^{16}$ En la modernidad sólida (la del fordismo, el keynesianismo, etc.), el individuo era socializado a través del adoctrinamiento, que se producía de arriba a abajo mediante el sistema educativo, los medios de comunicación, la ideología... En la modernidad líquida todo es más sutil y se intenta llegar a fines similares mediante la imposición de comportamientos que posibiliten la reproducción del sistema. En suma, los individuos deben desear hacer lo que es necesario para esa reproducción (Bauman, ib.: 97).

El individuo que empieza a formarse en los albores de los 70, de hecho, sigue la pauta de creerse más libre que antes (según Lipovetsky lo es, como comentábamos con anterioridad), sus actos tienen apariencia de voluntariedad, lo cual, hace que entienda su relación con los demás de una manera distinta al individuo del fordismo,

\footnotetext{
${ }^{15}$ Boltanski y Chiapello (2002) nos mostraron que el espíritu del capitalismo había cambiado. Los nuevos discursos legitimantes habían conseguido establecer una nueva narrativa que estabilizó y ayudó a construir el sistema actual. Podría decirse, siguiendo la terminología de Boltanski y Chiapello, que la postura de Lipovetsky es más neutra que la de Streeck respecto a este nuevo espíritu del capitalismo.

${ }^{16}$ Streeck en concreto hace referencia a la Vergesellschafftung de Simmel, que vendría a ser el modo en que los individuos se vinculan y, de este modo, encuentran su lugar en el mundo.
} 
que dependía en mayor medida de su situación de clase, oficio, familia, lugar de residencia, etc.

En un mercado maduro, comprar algo implica únicamente elegir lo mejor que me pueda permitir del infinito ramillete de posibilidades disponible, sin necesidad de negociar o comprometerse como ocurría en las relaciones sociales tradicionales. De hecho, los principales actores (además de los consumidores) en una estructura social de consumo avanzado son las empresas cuyos departamentos de marketing se especializan en adivinar todos nuestros deseos y satisfacerlos. [...] Estas empresas nunca discuten con los consumidores, simplemente escuchan y cumplen (Streeck, 2016a, 102).

La columna vertebral de la socialización mediante el consumo es la experiencia de la liberación de las cadenas del pasado a las que se refiere Lipovetsky, solo que para éste se trata de una emancipación real de ciertas ataduras anteriores, mientras que para Streeck y Bauman es una suerte de velo de maya con graves efectos morales. ${ }^{17}$ Según el sociólogo alemán, esta socialización es monológica (no dialógica), voluntaria en vez de impuesta, individual en lugar de colectiva. Además, las comunidades centradas en el consumo crean lazos mucho más frágiles, lo cual facilita pasar de una identidad a otra sin romper prácticamente con un pasado inexistente. Basta con cambiarse una foto del perfil de una red social e inscribirse en algún grupo de Facebook para considerarse "uno de ellos" (ib.: 103).

El cambio en la producción capitalista, que para el tema que nos ocupa se refiere a la ampliación masiva de la gama de productos ofertados, se agudizó en las décadas de los 80 y 90. Se podría hablar, de hecho Streeck lo hace, de una ingeniería social para reformar el espacio político y social (ib.:108). El consumismo generalizado, dio lugar a un individuo hedonista y, consecuentemente, a una "civilización hedonista" (Lipovetsky, 2006, 2016). Desde el punto de vista de Streeck, esto se encuadra en la batalla entre los mercados (Marktvolk) y la ciudadanía (Staatsvolk), ya que un debilitamiento de los segundos redunda directamente en beneficio de los primeros.

El sujeto sensualista surgido del capitalismo posfordista no encuentra incentivos para ejercer su condición de ciudadano. Streeck argumenta que, o se es un ciudadano consecuente (con todas las obligaciones sociales, políticas, morales, etc. que conlleva) o no se es. ${ }^{18}$ El ciudadano debe acatar las normas del juego democrático, elegidas en base a unas reglas abstractas e impersonales. Sin embargo, el consumidor se desenvuelve en un ecosistema de autocomplacencia, donde es el rey y solo debe dejarse llevar y cautivar. Sus decisiones, en vez de estar sometidas a compromisos con terceros y a reglas que lo constriñen, no suponen casi nunca un compromiso que no se pueda revocar fácilmente.

\footnotetext{
${ }^{17}$ Bauman, que de la terna de autores que aquí estamos tratando es el que más atención a los efectos morales de este nuevo modo de consumo, ha denominado "ceguera moral" (Bauman y Donskis, 2015).

18 Bauman llega a afirmar que "el consumidor es enemigo del ciudadano" (Bauman, 2018: 190).
} 
La participación política en una democracia exige capacidad para justificar y recalibrar nuestras elecciones a la luz de principios generales [...]. Al mismo tiempo, al contrario que al consumidor, al ciudadano se le exige que apoye, en términos generales, a la sociedad como a un todo [...]. Este compromiso tiene poco que ver con el que se genera en la compra de bienes y servicios [...]. A diferencia de la flexibilidad que caracteriza a las "comunidades de elección consumista", que surgen de las sociedades regidas por comportamientos de consumo, las comunidades políticas se definen por ser comunidades de destino. Su punto cardinal, en suma, es la exigencia a sus miembros de no incidir en su individualidad, sino en su identidad común, integrando aquélla en ésta (Streeck, 2016: 18).

Para el sociólogo alemán, la principal consecuencia del abandono de la figura del ciudadano es la pérdida de interés por la política de amplias capas de población, especialmente de la clase media. En las democracias liberales occidentales, el ciudadano medio de posguerra tenía cubiertas sus necesidades materiales, podía trazar planes de futuro para él y su familia, tenía círculos de interacción social definidos (iglesia, puesto de trabajo, sindicato, partido, club deportivo, etc.), y albergaba la esperanza de que la generación de sus hijos habitaría una sociedad más justa, más próspera y más bella que la suya. Esto no quiere decir que tuviera una vida fácil, pero sí con ciertas ventajas que acarreaban también previsibles obligaciones. En la nueva sociedad consumista, todo debe depender de uno mismo y responder a la lógica de la satisfacción individual.

En línea con las afirmaciones acerca de la relación entre ciudadanía y consumo, Colin Crouch, por su parte, lleva dos décadas realizando interesantes aportes. Uno de sus conceptos más conocidos es el de la posdemocracia, que sería el sistema político de las democracias liberales occidentales toda vez que éstas, por la acción del neoliberalismo, han dejado de ser democracias plenas. Desde su punto de vista, la ciudadanía política ha perdido la fuerza de antaño a manos del empuje de los mercados y las privatizaciones en masa que, desde finales de los 70, se vienen produciendo. El análisis de Streeck, como hemos visto en los primeros apartados del presente ensayo, es muy similar, pero pone el acento en las políticas sociales macroeconómicas, de empleo, educativas, etc. que la clase poderosa (Marktvolk) obliga al Estado a implementar.

El énfasis de Crouch es, sobre todo, político y legal. Ha estudiado, entre otras muchas cuestiones, las privatizaciones, sus desarrollos legales y sus efectos sociopolíticos, ya que, para el teórico británico, el despliegue del neoliberalismo a través de las privatizaciones en las últimas cuatro décadas ha supuesto un empobrecimiento del ethos democrático en las sociedades occidentales. En concreto, considera clave entender el paso de ser usuario de bienes públicos a consumidores de los mismos servicios en empresas privatizadas (2004, 2011, 2013). El usuario de servicios públicos, que podría identificarse con el ciudadano fordista cuando se beneficiaba de un servicio público, tenía en mayor o menor medida conciencia de estar utilizando un servicio al que había contribuido con su esfuerzo, materializado en los impuestos y las contribuciones sociales. Con el paulatino avance de las privatizaciones, ese sentimiento de pertenencia dio paso a la conciencia de consumidor, más relacionado 
con el individualismo y con la mercantilización de esferas hasta hace poco públicas. Se pasó del "yo soy parte de este servicio que nos beneficia a todos" a la mentalidad de la competencia y el mercado (buscar un precio eficiente que satisfaga mis necesidades, al menor precio y con la mayor calidad posible). En resumidas cuentas, si el neoliberalismo ha colonizado con prisa y sin pausa cada vez más aspectos de la realidad, también ha operado en nuestras mentes, tal y como nos muestran Crouch y en Bauman.

En consecuencia, esta tesis, aunque desde una perspectiva distinta, coincide con las conclusiones de Streeck sobre el consumo y la ciudadanía, a saber: la batalla de las oligarquías económicas por la toma del poder se ha realizado para aumentar sus cuotas de poder y beneficios, pero, además, ha sabido utilizar magistralmente el arma del consumo para la construcción de un nuevo individuo hedonista, consumista e individualista que, después de todo, se parece cada vez más al que nos presenta la teoría económica neoclásica y sus elecciones racionales.

Resulta curioso, por no decir desconcertante, cómo las objeciones a la falta de apego de la teoría neoclásica de la economía a la realidad (con la sombra de duda que proyecta sobre su utilidad y legitimidad), realmente estén coadyuvando a operar estos cambios en la realidad. En otras palabras, no somos robinsones, ${ }^{19}$ pero, gracias, entre otros motivos, a las teorías económicas de la elección racional y a su implementación, nos están convirtiendo en robinsones. ${ }^{20}$

\section{CONCLUSIONES}

De todos modos, hay que reconocer que, en cierto modo, los teóricos de la elección racional no andan muy desencaminados cuando definen el patrón de toma de decisiones individuales como una maximización de la utilidad o "felicidad" que pueden reportarles. El problema, desde el punto de vista de Streeck y Crouch, es la generalización de esa pauta de comportamiento. El ser humano no actúa así porque esa sea su lógica "natural", sino porque se le ha inculcado gracias a un severo plan de socialización que tenía como objetivos claros una salida a un estancamiento económico en los 70, y una debilitación del ethos político que representaban las instituciones del fordismo (Streeck, ib.: 111).

Como se colige de los primeros apartados de este ensayo, la situación actual de la sociedad es el resultado de un proceso que poco tiene que ver con una naturaleza racional de los sujetos reducida a la lógica de la búsqueda de la mayor utilidad. El neoliberalismo se ha impuesto mediante políticas concretas y decisiones que, si bien es cierto que buscan el beneficio particular de unos pocos, nada tiene que ver con los mercados eficientes que la teoría económica nos presenta. No hay igualdad de oportunidades ni información accesible para todos lo participantes. Ocurre más bien

\footnotetext{
${ }^{19}$ Que es la metáfora arquetípica de la teoría económica ortodoxa actual.

${ }^{20} \mathrm{Y}$ digo gracias a ellas porque las medidas económicas que se llevan a cabo, normalmente, tienen como justificación los complejos modelos macroeconómicos de esta escuela económica. De ahí, como nos muestran Crouch y Streeck provienen los cambios en nuestra mentalidad.
} 
al contrario, como nos han mostrado numerosos autores, ${ }^{21}$ cuando algunos actores del mercado tienen más poder que otros lo aprovechan para acaparar más cuotas de influencia que, a su vez, les proporcionan una mejor posición de la que sacar provecho. Streeck nos muestra que el Estado es tomado como rehén por los mercados para, precisamente, lograr mayor capacidad de influencia y beneficios. La devaluación del Estado fuerte del fordismo ha provocado, a su vez, un empobrecimiento de la calidad de la ciudadanía, cuyo lugar, como hemos intentado mostrar aquí desde las perspectivas de Lipovetsky, Bauman y Streeck, ha sido ocupado por el consumismo.

Lo más preocupante del asunto es que, como apuntan Bauman, Streeck y Crouch (en esto se desmarca con reservas Lipovetsky), el paso del ciudadano al consumidor deja poca esperanza para la regeneración política. Simplemente no hay incentivos para despertar las conciencias democráticas. Ante esta situación, podríamos formularnos la eterna pregunta kantiana de qué nos es dado esperar. Pese a las similitudes de los diagnósticos, los planteamientos de alternativas futuras divergen. ${ }^{22}$

Según Streeck, nos encontramos en un punto de muy difícil retorno. Su visión del interregno como transición al postcapitalismo deja poco lugar a la esperanza. Además, la sustitución del ciudadano por el consumidor hace todavía más difícil la ruptura del círculo vicioso: si los individuos carecen de interés en la política porque han sido socializados por y en el consumismo, ¿quién plantará cara a las élites de los mercados para conseguir de algún modo volver a nivelar la balanza? La democracia necesita ciudadanos conscientes de serlo y comprometidos con su situación; del mismo modo, estos necesitan instituciones políticas capaces generar un ethos democrático consistente, lo cual implica, desde la óptica de Streeck, unas instituciones capaces de ser un contrapeso a la clase dominante, y no un mero "Estado depredador" en palabras de James K. Galbraith (2008).

Para Crouch, a pesar de su cruda descripción del funcionamiento del sistema capitalista actual, todavía se entrevé un rayo de esperanza. Cree que aún es posible reforzar instituciones como los sindicatos y los partidos políticos para dar un giro sustancial a la socialdemocracia. Crouch distingue entre la socialdemocracia defensiva y la asertiva (Crouch, 2013). La primera sería la de la tercera vía, centrada en el mejor caso en minimizar daños intentando no molestar en exceso a los mercados. La segunda toma como ejemplo a las socialdemocracias nórdicas de la posguerra, y en especial su actitud combativa frente al Marktvolk. Sólo así, en opinión

\footnotetext{
${ }^{21}$ Véase, por ejemplo, Stiglitz $(2010,2015)$.

${ }^{22}$ Luis Enrique Alonso y Carlos J. Fernández presentan esta problemática desde la perspectiva de la innovación social y su relación con los discursos del gerencialismo (2018.: 67-74) El cambio del espíritu capitalista se resume, para estos autores, en el paso de la empresa moderna-fordista a la postmoderna-posfordista (2018: 40 ss.). En concreto, ellos muestran cómo la innovación, al abrigo de este cambio de espíritu, ya no es una cuestión social, sino que con el advenimiento de las nuevas formas empresariales postmodernas, se convierte en algo exclusivamente individual y, por tanto, competitiva ("yo soy más genial que el otro"). Este punto de vista que nos presentan Alonso y Fernández ayuda explicar, desde otro ángulo este ocaso social, al que Streeck hace referencia.
} 
de Crouch (2013: 83), la clase trabajadora tendrá el orgullo y la confianza necesaria para intentar cambios sociales de profundo calado que hagan del sistema capitalista algo más justo. El consumismo impulsado por la oleada neoliberal, que ha convertido al usuario de bienes públicos en consumidor, no parece, en opinión de Crouch, un punto de no retorno.

Bauman muestra una visión cercana a la de Crouch, aunque en un tono más amable. La sociedad consumista ha implantado un modo de entender el mundo y la vida que ha arruinado valores imprescindibles para la convivencia democrática. En eso coincide con Crouch y Streeck, pero el punto que él considera más relevante es la singularización de los individuos, el hecho de que se haya inoculado un modo de comportamiento que recluye en sí mismo al habitante de nuestras sociedades. Eso genera una sociedad atomizada, que no es sino un sumatorio de entes independientes cuyas decisiones vitales tienen que ver sobre todo con el consumo (Bauman, 2009). ${ }^{23}$ El individuo se ve dominado por una pulsión compradora, una especie de fuego interior insaciable que dirige nuestra mirada siempre y exclusivamente hacia la próxima adquisición. Su libertad, en opinión de Bauman, se ve, por consiguiente, severamente cuestionada al verse recluida al ámbito de lo comercial (2008: 138). Sin embargo, al igual que para Crouch, considera que sigue habiendo esperanza, y ésta reside en el Estado de corte socialdemócrata, cuya principal función es «defender a la sociedad de los "daños colaterales"» del consumismo (Bauman, 2009: 143). ${ }^{24}$

No deja de ser llamativo que, para estos tres autores, en el corazón de la problemática consumo-ciudadanía se encuentre el Estado. Aunque, a decir verdad, no podía ser de otro modo. Si las raíces mismas del neoliberalismo se hunden en el ataque de las élites económicas a las restricciones al capital, el Estado siempre tendrá algo que decir, y, cuando deje de tener la fuerza necesaria para hacerlo, muy probablemente lleguemos al escenario de postcapitalismo del que nos advierte Streeck. Por consiguiente, podríamos afirmar a la luz de los temas esbozados en este artículo, que la hipótesis de que el consumo juega un papel vital para acabar con la "racionalidad" sólida-fordista-keynesiana de posguerra encarnada en el Estado socialdemócrata es, cuando menos, digna de ser tenida en cuenta.

\footnotetext{
${ }^{23}$ Esta consecuencia es especialmente grave para Bauman dada la influencia de la filosofía de Levinas en su pensamiento. El rostro del Otro, para el filósofo franco-lituano, constituye toda subjetividad y es anterior a cualquier experiencia, al tiempo y a la misma conciencia. El rostro del Otro funda nuestra subjetividad, nuestro "Yo", y esto tiene profundas consecuencias éticas (Levinas, 2011). Lógicamente, el abandono del Otro implica la pérdida de la fundamentación ética del ser humano. De ahí la "ceguera moral" de la que nos advierte Bauman.

${ }^{24}$ Aunque del tono de la breve cita aportada pueda parecer lo contrario, Bauman no estaría en la línea de la socialdemocracia defensiva que criticaba Crouch, sino en la asertiva. El tema del presente ensayo sobrepasa el estudio de las diferencias de sus posiciones políticas.
} 


\section{BIBLIOGRAFÍA}

ALONSO, Luis Enrique. (2005). La era del consumo. Madrid: Siglo XXI.

- y FERNÁNDEZ, Carlos J. (2018). Poder y sacrificio. Los nuevos discursos de la empresa. Madrid: Siglo XXI.

BAUMAN, Zygmunt. (2002). Modernidad líquida. Buenos Aires: FCE.

- (2008). Does Ethics have a Chance in a World of Consumers? Cambridge (Ma)/London: Harvard University Press.

— (2009). Vida de consumo. México D. F.: FCE.

— (2013). Vidas desperdiciadas: La modernidad y sus parias. Barcelona: Paidós.

BAUMAN, Zygmunt; DONSKIS, Leonidas. (2015). Ceguera moral. La pérdida de sensibilidad en la modernidad líquida. Barcelona: Paidós.

BECK, Ulrich. (2015). La sociedad del riesgo. Hacia una nueva modernidad. Barcelona: Paidós.

BOLTANSKI, Luc; CHIAPELLO, Eve. (2002). El nuevo espíritu del capitalismo. Madrid: Akal.

CASTELLS, Manuel. (Dir., 2017). Otra economía es posible. Cultura y economía en tiempos de crisis. Madrid: Alianza Editorial.

CROUCH, Colin. (2004). Post-Democracy. Cambridge/Malden: Polity.

— (2011). The Strange Non-Death of Neoliberalism. Cambridge/Malden: Polity.

— (2013). Making Capitalism Fit for Society. Cambridge/Malden: Polity.

- (2016). The Knowledge Corrupters. Hidden Consequences of the Financial Takeover of the Public Life. Cambridge/Malden: Polity.

FOUCAULT, Michel. (2009). El nacimiento de la biopolítica. Cursos del Collège de France (1978-1979). Madrid: Akal.

GALBRAITH, James K. (2008). The Predator State. New York/London: Free Press

- (2016). Desigualdad y equilibrio. La economía mundial antes de la crisis. Barcelona: RBA.

HAYEK, Fredrich. (1980). The Economic Conditions of the Interstate Federalism, en Individualism and Economic Order. Chicago: Chicago University Press. [1939].

LAVAL, Christian; DARDOT, Pierre. (2017). La pesadilla que no acaba nunca. Barcelona: Gedisa.

- (2013). La nueva razón del mundo. Barcelona: Gedisa.

LEVINAS, Emmanuel. (2011). De otro modo que ser o más allá de la esencia. Salamanca: Sígueme.

LIPOVETSKY, Gilles. (2006). La era del vacío. Ensayos sobre el individualismo contemporáneo. Barcelona: Anagrama. 
— (2016). De la ligereza. Barcelona: Anagrama.

LUHMANN, Niklas (1990). Political Theory in the Welfare State. New York/Berlín: De Gruyter.

MILIBAND, Ralph. (2015). Class War Conservatism and other Essays. London/New York: Verso.

MUSGRAVE, Robert. (1992), Schumpeter's crisis of the tax state: An essay in fiscal sociology. Journal of Evolutionary Economics, 2 (2), 89-113. https://doi.org/10.1007/BF01193535

NACHTWEY, Oliver. (2017). La sociedad del descenso. Precariedad y desigualdad en la era posdemocrática. Barcelona: Paidós.

PALAZUELOS, Enrique. (Dir., 2015). EConomía política mundial. Madrid, Akal.

PIKETTY, Thomas. (2015). El capital en el siglo XXI. Barcelona: RBA.

SÁNCHEZ-CUENCA, Ignacio. (2014). La impotencia democrática. Madrid: Catarata.

SCHUMPETER, Joseph. (2009). Can Capitalism Survive? Creative Destruction and the Global Economy. New York: Harper Perennial Modern Classics.

- (1991) The Economics and Sociology of Capitalism. Princeton: Princeton University Press.

SRNICEK, Nick; WILLIAMS, Alex. (2016). Inventar el futuro. Poscapitalismo y un mundo sin futuro. Barcelona: Malpaso.

STIGLITZ, Joseph E. (2010). Freefall. America, Free Markets, and the Sinking of the World Economy. New York/London: W. W. Norton \& Company.

- (2015). El precio de la desigualdad. Barcelona: Penguin Random House.

STREECK, Wolfgang. (2009). Re-Forming Capitalism. Institutional Change in the German Political Economy. New York: Oxford University Press.

- (2014). The Politics of Public Debt: Neoliberalism, Capitalist Development, and the Restructuring of the State, German Economic Review, 1, 143-165. DOI: 10.1111/geer.12032

- (2016a). How Will Capitalism End?. London/New York: Verso. Edición en casteIlano (2017). ¿Cómo terminará el capitalismo?. Madrid: Traficantes de Sueños.

- (2016b). The Post-Capitalist Interregnum: The Old System is Dying, but a New Social Order Cannot Yet Be Born. Juncture, p.: 68-77. DOI: 10.1111/newe.906

- (2017). The Return of the Repressed. New Left review, 104.

- (2017). Buying Time. The Delayed Crisis of Democratic Capitalism. London/ New York: Verso. Edición en castellano (2016). Comprando tiempo. Madrid: Katz.

TORTELLA, Gabriel. (2000). La revolución del siglo XX. Capitalismo, comunismo y democracia. Madrid: Taurus.

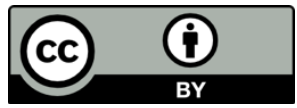

